\title{
Histological and ultrastructural studies of the pancreas of native rabbits (Oryctolagus cuniculus)
}

\author{
Y.A. Mohammed \\ Department of Theriogenology, Anatomy and Physiology, Collage of Veterinary Medicine, University of Duhok, Duhok, Iraq \\ email: yhyam1967@gmail.com
}

(Received September 29, 2018; Accepted January 2, 2019)

\begin{abstract}
The pancreas of male adult native rabbit was studied by using light microscope (LM) and transmission electron microscope (TEM). The pancreas possessed both exocrine and endocrine portions. Exocrine portion included both acinar and ductal cells. The acinar cells were pyramidal in shaped which formed the lining epithelia of secretory units (acini). The apical cytoplasm of acinar cells contained unequal size and variable electron opacity of zymogen granules, while the basal part occupied by welldeveloped rough endoplasm reticulum (rER). Short microvilli projected from the free surfaces of both acinar and ductal cells. The lateral cell membranes of adjacent acinar and ductal cells adhere apically by junctional complex, which was composed of zonulae occludens and zonulae adherens. There was notable interdigitating between the lateral cell membranes of neighboring ductal cells that were located beneath the junctional complex. The oval or irregular pancreatic islets consisted of $\beta, \alpha$ and $\delta$ endocrine cells. Both $\beta$ - and $\alpha$-cells could be demonstrated by using LM and TEM, whereas $\delta$-cells visualized with TEM only. The cytoplasm of $\beta$-cells contained purple granules and $\alpha$-cells showed yellowish granules in their cytoplasm when stained with aldehyde fuchsine method. At ultrastructure level, the cytoplasmic granules of $\beta$-cells were identified by homogenous electron dense core with clear hallo zone, the numerous granules of $\alpha$-cells had very electron dense granules and $\delta$-cells contained few granules similar to those of $\alpha$-cells. $\beta$ - or $\alpha$-cells inserted as a single cell and in a partial manner between the ductal cells of some ducts.
\end{abstract}

Keywords: Pancreas, Native rabbit, Light microscope, Transmission electron microscope.

Available online at http://www.vetmedmosul.com

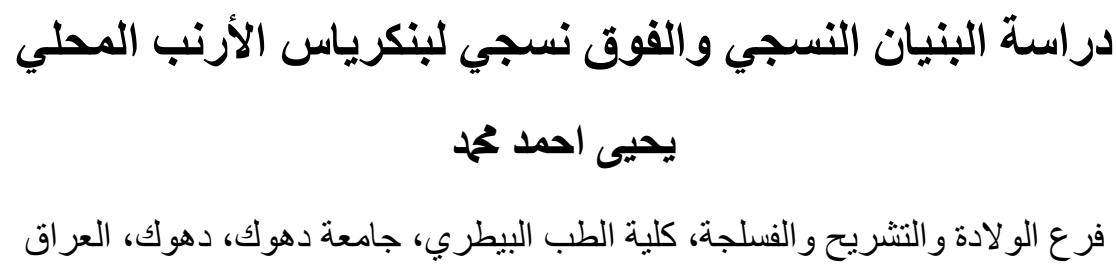

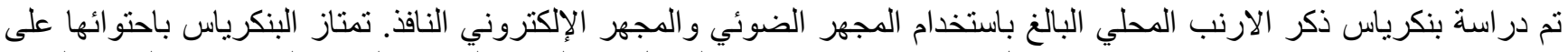

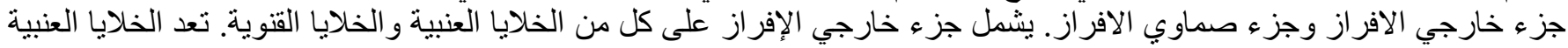

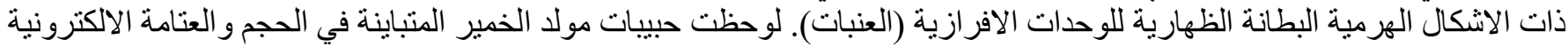

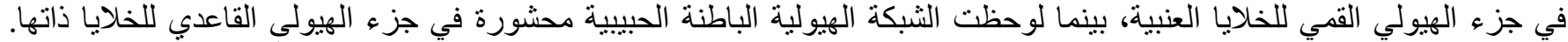

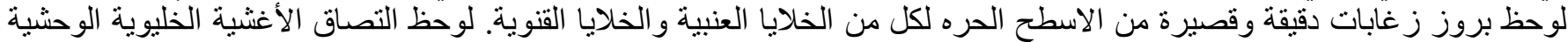

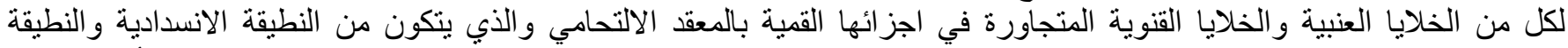

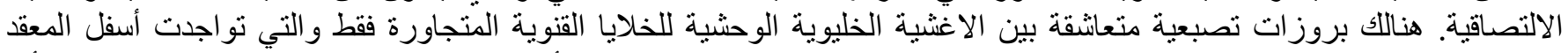

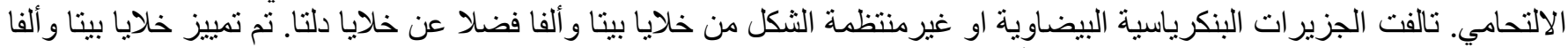

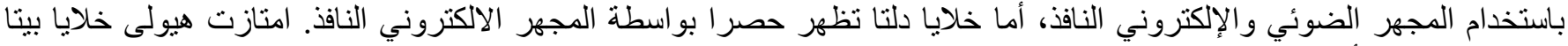

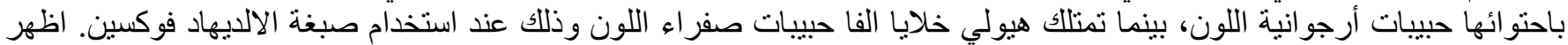




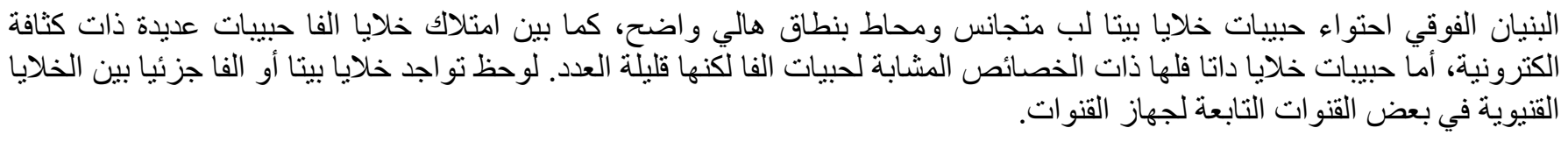

\section{Introduction}

The pancreas was a peculiar organ in the body where it contained both exocrine and endocrine; the exocrine portion consisted of numerous tubuloacinar secretory units which secreted pancreatic juice containing enzymes, ions and water. Pancreatic enzymes were responsible for digestion of proteins, carbohydrates and lipids. This was reflected in the absorption of these substances from the small intestine and then reflected on the animal's food representation. Clusters of epithelial cells (pancreatic islets or islets of Langerhans) were scattered among the secretory units and formed the endocrine portion which produced the hormones (1-3). The pancreas was considered as a target organ for both diabetes mellitus and pancreatic cancer, therefore it had medical importance (4). Rabbits had an economic significance and they were commonly used in the laboratory. They were extensively employed in teaching. Recently, the rabbits were also kept as pet animals (5). As a result of these scientific facts placed the rabbit and their pancreas in the focus of research, so it has been planned to conduct histological and ultrastructural studies of this organ in native rabbit.

\section{Materials and methods}

The present research was achieved on 8 male adult native rabbits. The rabbits were gathered from Semeel town-Duhok governorate, Iraq. The body weight of the animals ranged between $2.5-3 \mathrm{~kg}$. The physical examination was used to determine healthy status of animals. All rabbits were kept in wide room of project of animal breeding, college of veterinary medicine, university of Duhok; food and water were provided ad libitum. Each rabbit was slaughter and dissected individually.

The specimens were obtained from all parts (head, body and tail) of rabbit pancreas, washed with normal saline solution to eliminate the blood and other adhering wreckages. Some of these specimens immersed in formal saline, while the other in Bounis fluid. The paraffin embedded technique was employed to realize thin slices of tissue sections (5-6 $\mu \mathrm{m}$ thickness) that were stained with Gill's hematoxylin and eosin (H\&E), Alcian blue ( $\mathrm{pH} 2.5)$, Masson's trichrome and aldehyde fuchsine $(6,7)$. The slides were examined and photograph in center public health laboratory, Duhok city by using a photomicroscope (Olympus, Japan) and digital sight controller-microscope camera control unit (Nikon, Japan).
Other specimens of rabbit pancreas were fixed in paraformaldehyde-glutaraldehyde in phosphate buffer and then transferred to Cairo city- Egypt. The post fixation, dehydration and embedding of the tissue specimens were performed according to protocol of transmission electron microscopic unit in regional center of the mycology and biotechnology, Al-Azhar University, Cairo, Egypt.

\section{Results}

\section{Gross inspection}

The gross inspection exhibit that the pancreas of native rabbit composed of three lobes; head, body and tail (Figure1). Anatomical positions of these lobes and their topographical relationships had been revealed in previous study (8). Therefore, our results in the current research would be restricted to histological and ultrastructural studies.

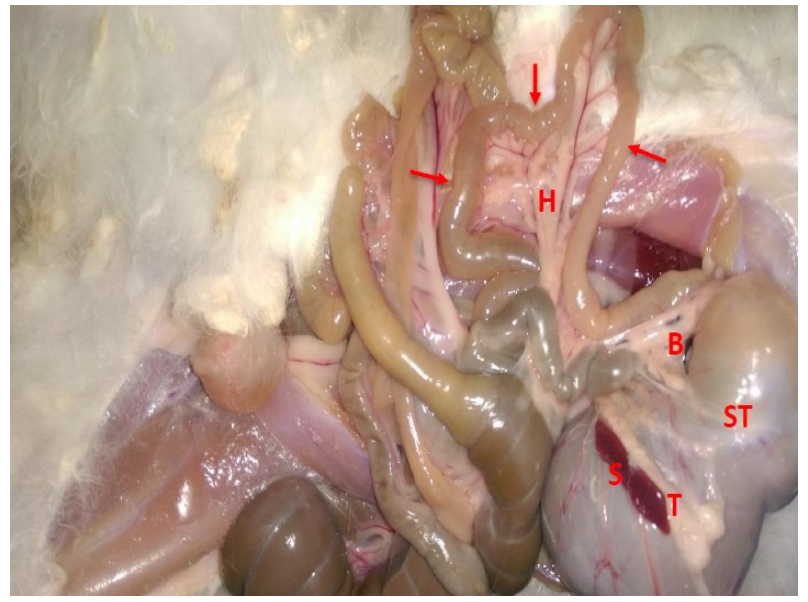

Figure 1: Photograph of rabbit pancreas showing: head lobe $(\mathrm{H})$, body (B) and tail lobe (T), duodenal U-shaped (arrows), stomach (ST) and spleen (S).

\section{Histological observations}

The head and body of native rabbit pancreas had dispersed microscopic lobules (Figure 2), while the tail appeared as a compact part (Figure 3). As a whole, pancreas was surrounded by a thin capsule of connective tissue mainly composed of collagen fibers and enveloped by layer of adipose tissue (Figs. 3). Very thin trabeculae separated the pancreatic lobules. These trabeculae confluent and became thick where surrounding the interlobular blood and lymph vessels as well as ducts (Figure 4). The pancreas 
of rabbit included both exocrine (pancreatic acini and duct system) and endocrine parts (pancreatic islets or islets of Langerhans).

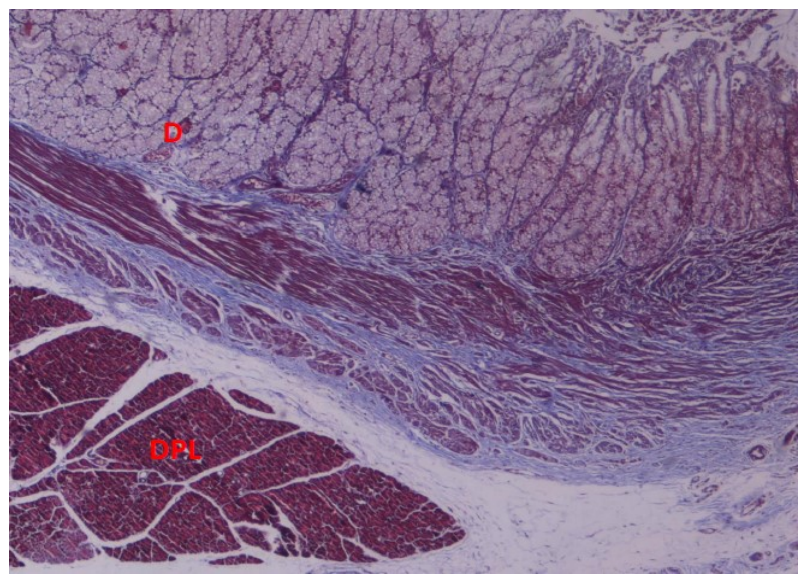

Figure 2: Microphotograph of rabbit pancreas (head lobe) showing: dispersed pancreatic lobules (DPL) and duodenum (D). Masson trichrome stain: X4.

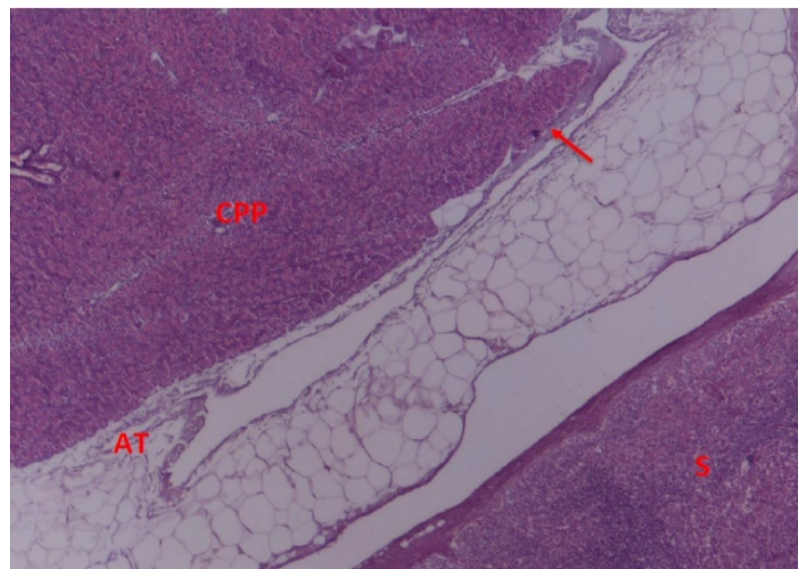

Figure 3: Microphotograph of rabbit pancreas (tail lobe) showing: com pact pancreatic part (CPP), capsule (arrow), layer of adipose tissue (AT) and spleen (S). H \& E stain: X4.

\section{Exocrine pancreas}

The pancreas was considered as a compound tubuloacinar gland with the predominance of acini portions. It should be noted that a few of acini were visualized as typical units. Each typical acinus was lined by single layer of pyramidal serous cells surrounding a very narrow lumen (Figure 5). The rounded nuclei were located in the basal portions of the acinar cells. The apical cytoplasm was acidophilic due to containing zymogen granules, whereas the basal part appeared dense basophilic, because it contained abundant rough endoplasmic reticulum (rER).
The duct system consisted of intercalated, intralobular, interlobular and accessory pancreatic ducts. The main pancreatic duct was absent. The initial cells of the intercalated duct formed small ducts extend into the lumen of the acinus as a centroacinar cells (Figure 5). The nuclei of these cells were oval or spherical in shaped. The intercalated duct had less diameters than surrounding pancreatic acini, whereas the diameter of intralobular ducts was more than that of intercalated duct and pancreatic acini. Both ducts were lined by flattened or low cuboidal cells with elongated oval nuclei. The cytoplasm of both ducts was scant and less acidophilic. The interlobular duct was surrounding by connective tissue (Figure 4) and lining by cuboidal cells with rounded nuclei. The lateral cell boundaries between the ductal cells of the preceding ducts were not clear.

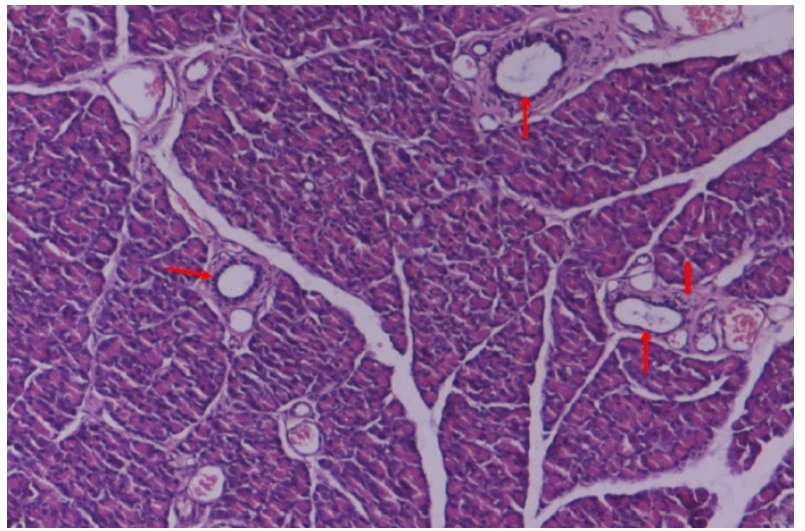

Figure 4: Microphotograph of rabbit pancreas showing: interlobular ducts (arrows) and interlobular connective tissue (Line). H \& E stain: X10.

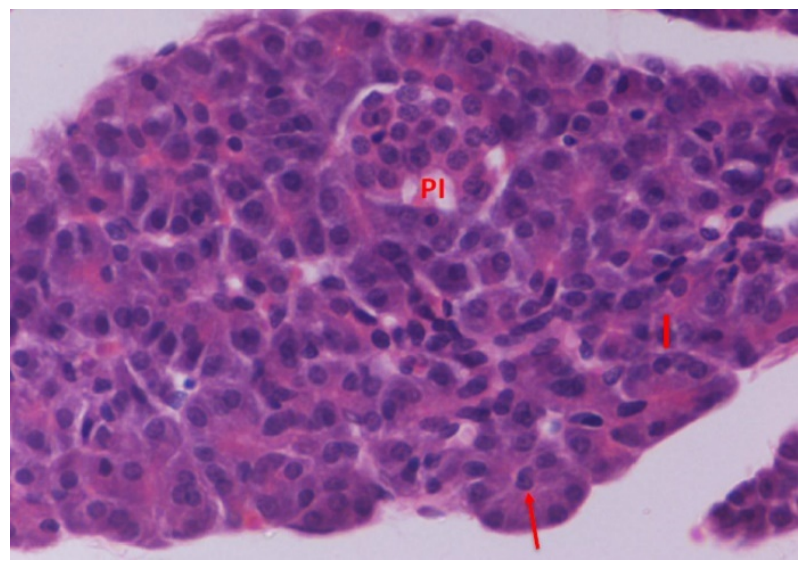

Figure 5: Microphotograph of rabbit pancreas showing: pancreatic islet (PI), pancreatic acinus (Line) and centroaciner cell (arrow). H \& E stain: X40. 
The native rabbit had accessory pancreatic duct. This duct was enveloped by well-developed capsule of collagenous connective tissue containing fibroblasts and small blood vessels. The initial part of the duct was surrounded with pancreatic lobules (Figure 6), whereas the ending part is a free of lobules and directed towards the wall of the duodenum. The lining epithelium of the accessory duct composed of three cell types; simple columnar, basal and goblet cells (Figure 7). Goblets cells were more numerous in the ending part of accessory duct that colored blue with Alcian blue stain, $\mathrm{pH} 2.5$ (Figure 8).

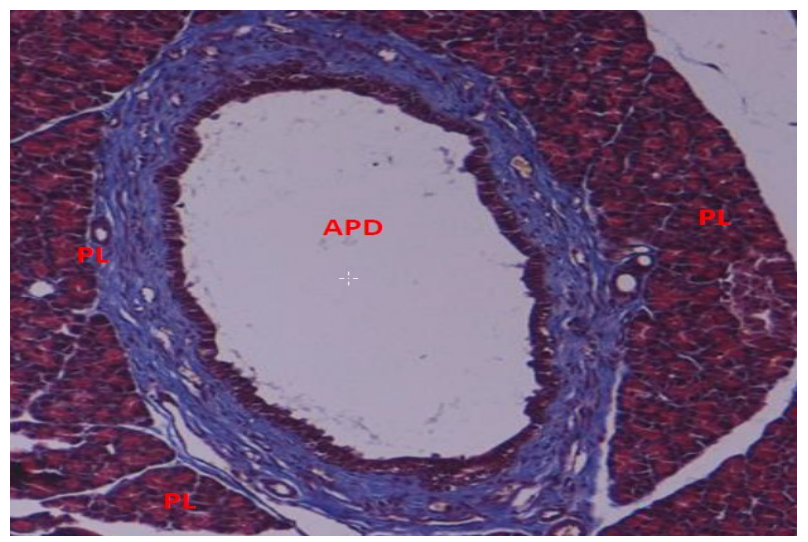

Figure 6: Microphotograph of rabbit pancreas showing: initial part of accessory pancreatic duct (APD) and pancreatic lobules (PL). Masson trichrome stain: X10.

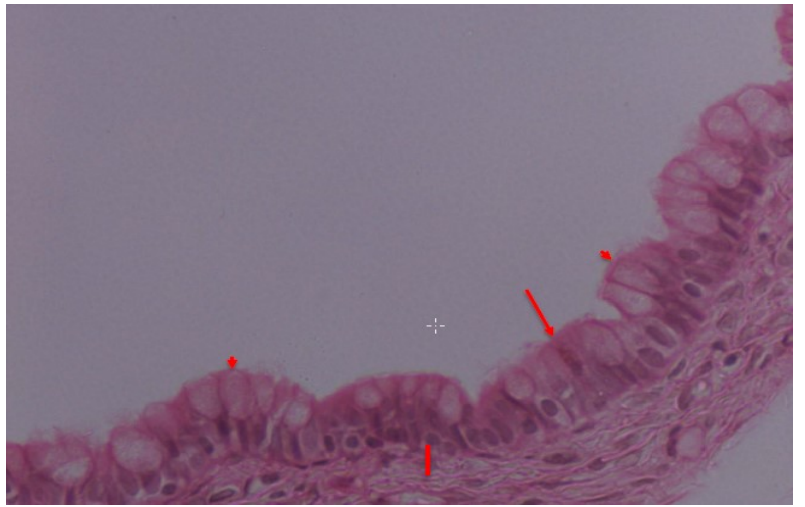

Fig 7: Microphotograph of rabbit accessory pancreatic duct (final part) showing: goblet cells (arrow heads), columnar cell (arrow) and basal cell (Line). H \& E stain: X40.

\section{Endocrine pancreas}

With $\mathrm{H}$ and $\mathrm{E}$ stain, the pancreatic islets appeared as oval or irregular clusters of epithelial cells scattered randomly throughout the pancreatic lobules (Figure 5). Two endocrine $\beta$ - and $\alpha$-cells could be identified when using aldehyde fuchsine stain. $\delta$-cells did not show any reactional stainability with the latter dye. The number of $\beta$-cells were larger and more numerous than $\alpha$-cells. Both cells possessed polygonal shaped. The cytoplasm of $\beta$-cells contained purple granules, while cytoplasm of $\alpha$-cells had yellowish granules (Figures 9 and 10). The distribution of these cells was varied within the pancreatic islets. There were two patterns of pancreatic islets present in all parts of rabbit pancreas. The first pattern of islets contained centrally located $\beta$-cells and peripheral $\alpha$-cells (Figure 9). In contrast to this, the second style of islets had centrally position of $\alpha$-cells (Figure 10). Pancreatic islets were furnished by numerous capillaries which they were situated either in the center of islets or they were located at their periphery (Figures 9 and 10).

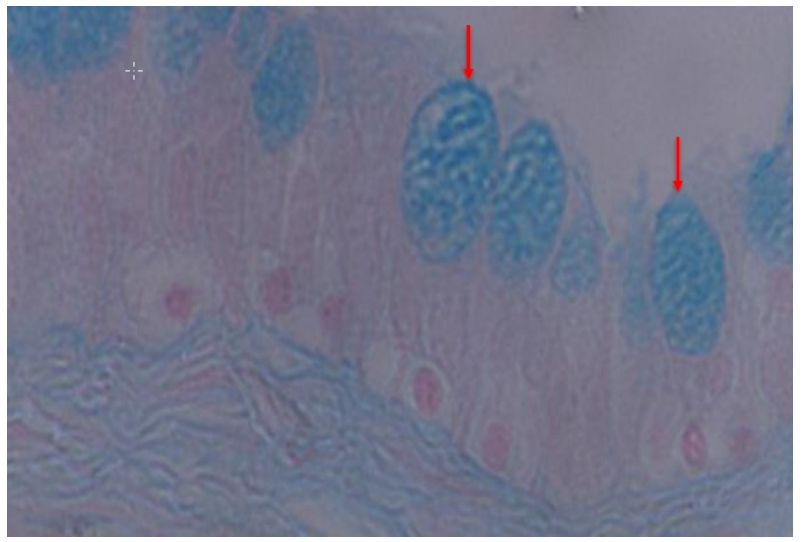

Figure 8: Microphotograph of rabbit accessory pancreatic duct (final part) showing: goblet cells (arrows). Alcian blue stain $\mathrm{pH}$ 2.5: X100.

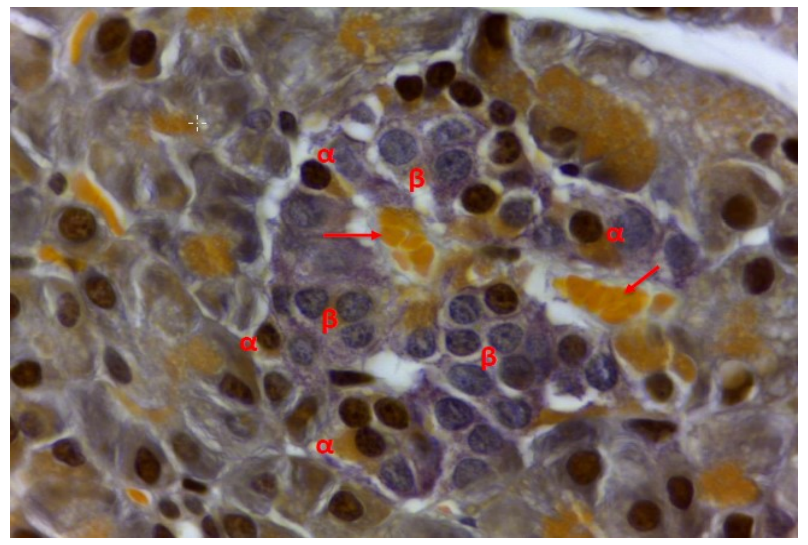

Figure 9: Microphotograph of rabbit pancreas (pancreatic islet) showing: $\alpha$-cells containing yellowish granules in their cytoplasm, $\beta$-cells containing purple granules in their cytoplasm and capillaries (arrows). Aldehyde fuchsin stain: X100. 


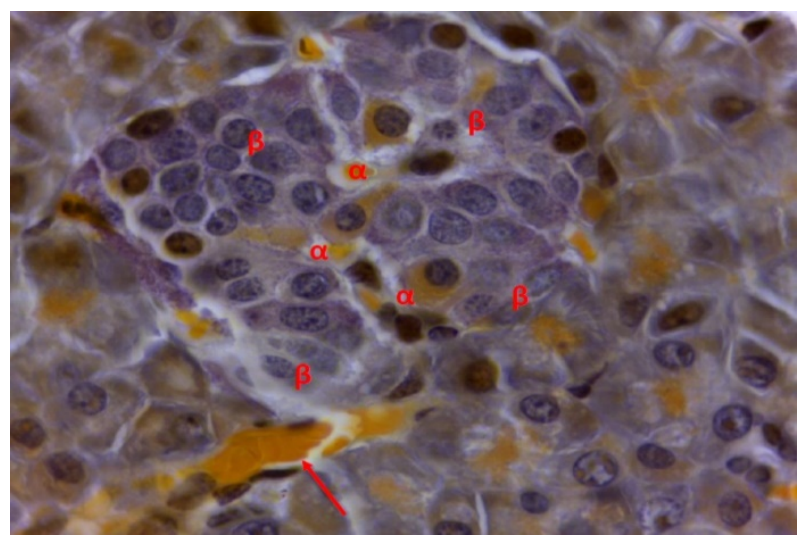

Figure 10: Microphotograph of rabbit pancreas (pancreatic islet) showing: $\alpha$-cells containing yellowish granules in their cytoplasm, $\beta$-cells containing purple granules in their cytoplasm and capillaries (arrow). Aldehyde fuchsin stain: X100.

\section{Ultrastructural observations Exocrine pancreas}

Pancreatic acinar cells possessed electron dense cytoplasm containing secretory granules (zymogen granules) mostly situated in the apical region. These granules were variable in size and in electron opacity. In general, well-developed rER was positioned in the basal part, but sometimes this organelle was tended to be distribute thought the cytoplasm. Prominent Golgi apparatus, mitochondria and lysosomes were also showed within the cytoplasm. Rounded or irregular shaped nuclei containing both euchromatin and heterochromatin were located in deep area of the cell (Figure 11). Short microvilli were originating from the free surface of acinar cells and projecting into the lumen. The lateral cell membranes of adjacent acinar cells adhere apically by junctional complex. This juncture included zonulae occludens at the apical end and zonulae adherens promptly beneath them (Figure 12).

The centroacinar cells had large, brighter nuclei and their scant cytoplasm had electron light appearance. Intercalated, intralobular and interlobular ducts as well as accessory pancreatic duct (columnar cells) had the same features when viewed by TEM. The free surface was provided with short microvilli. The lateral cell membranes of the neighboring ductal cells were equipped by same junctional complex of the acinar cells. In addition to the junctional complex, numerous notable interdigitating was interposed adjacent ductal cells along the intermediate and basal portions of their lateral surfaces (Figure13). Occasionally, the interdigitating appeared in basal cell membrane of the ductal cells which was directed toward undulating basal lamina (Figure 14).

Endocrine cells ( $\alpha$ - or $\beta$-cells) were present as a single cell and in a partial manner between the ductal cells, but did not reach the lumen (Figure14). These cells inserted mainly within the interlobular and main accessory ducts.

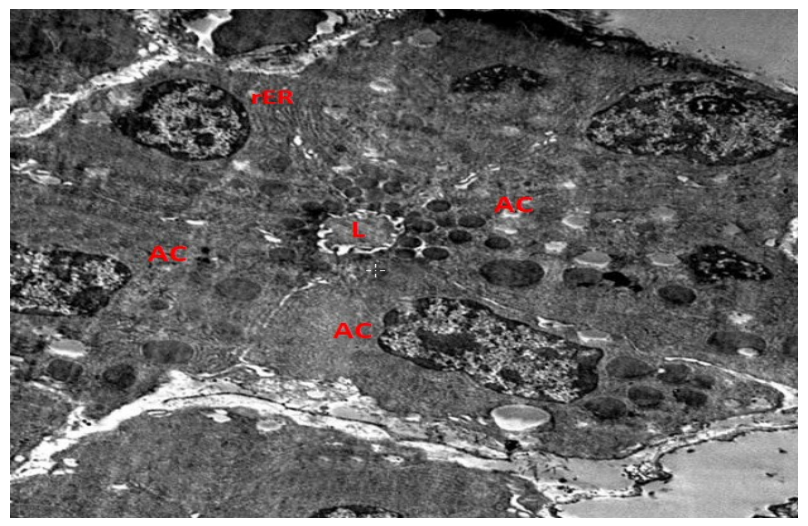

Figure 11: Transmission electron micrograph of rabbit pancreas (pancreatic acinus) showing: acinar cells (AC) containing zymogen granules, rough endoplasmic reticulum (rER) and Lumen (L). $6000 \mathrm{X}$.

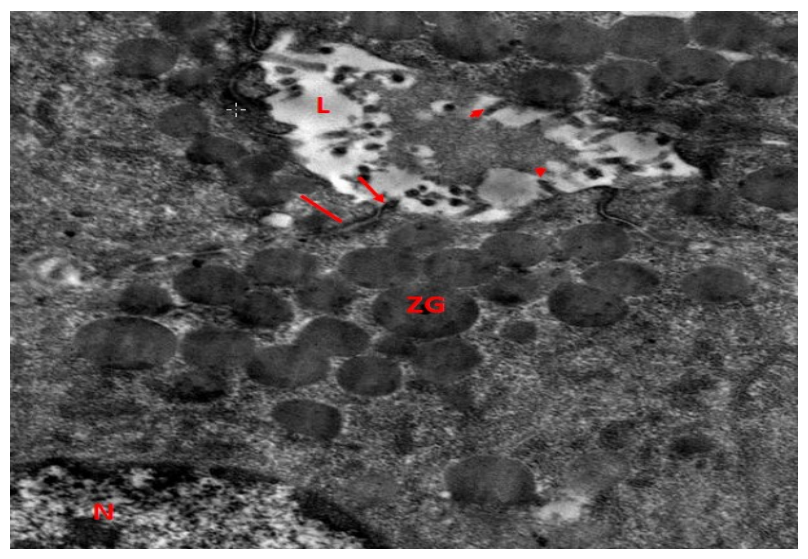

Figure 12: Transmission electron micrograph of rabbit pancreas (acinar cell) showing: nucleus $(\mathrm{N})$, zymogen granules (ZG), lumen (L) containing secretion, microvilli (arrow head), zonula occludens (arrow) and zonula adherans (line). $20000 \mathrm{X}$.

\section{Endocrine pancreas}

Three different endocrine cells; $\alpha, \beta$ and $\delta$ could recognized in the pancreatic islet of native rabbit depending on their ultrastructural characteristics.

$\beta$-cells possessed large, oval or irregular triangular shaped nuclei with striking one or two nucleoli (Figure 15). Many secretory granules (unequal size) were distributed evenly within the cytoplasm. These granules identified by homogenous electron dense core with clear hallo zone (Figure 16). 


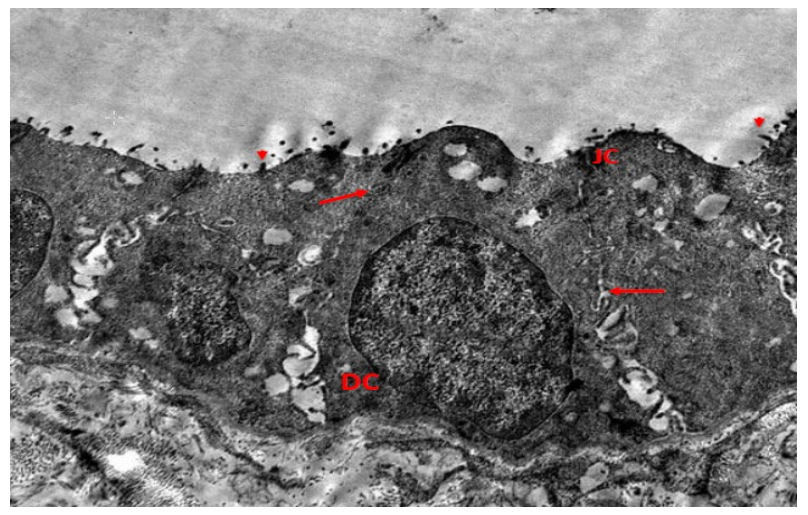

Fig 13: Transmission electron micrograph of rabbit pancreas (interlobular duct) showing: ductal cell (DC), junctional complex (JC), microvilli (arrow heads) and lateral interdigitating (arrows). $10000 \mathrm{X}$.

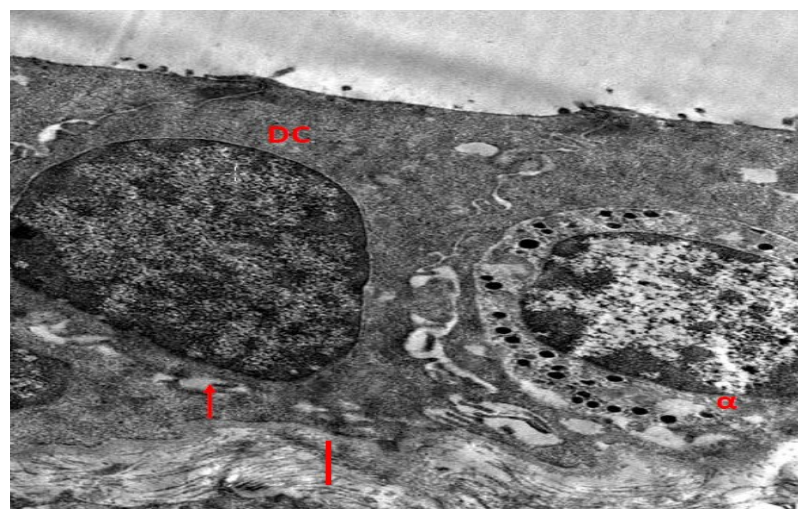

Figure 14: Transmission electron micrograph of rabbit pancreas (interlobular duct) showing: ductal cell (DC), $\alpha$ cell, basal interdigitating (arrow) and basal lamina (line). $15000 \mathrm{X}$.

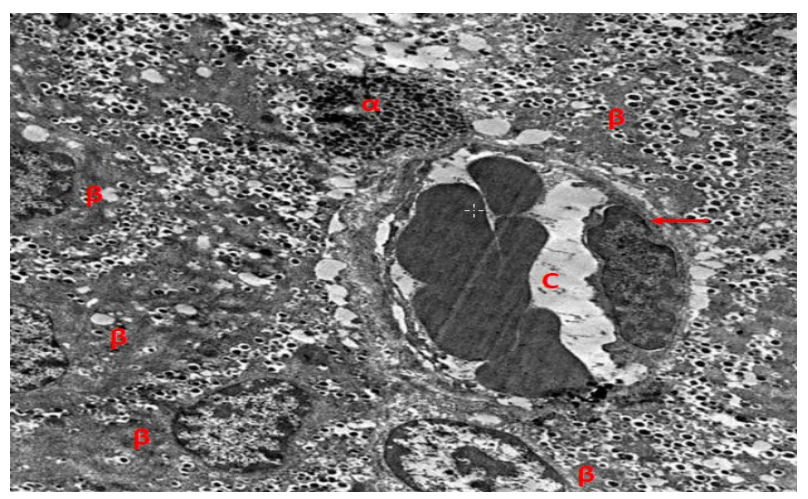

Figure 15: Transmission electron micrograph of rabbit pancreas (pancreatic islet) showing: numerous $\beta$-cells, $\alpha$ cell close to capillary, capillary (C) and its endothelial cell (arrow). $8000 \mathrm{X}$.
The nuclei of $\alpha$-cells were oval in form. The cytoplasm of $\alpha$-cells contained very dense electron secretory granules without a clear hallow zone. The granules were varying in size and they spread anywhere inside the cytoplasm with the possibility of presence their majority at one aspect of the cell (Figure 16).

$\delta$-cells characterized by large irregular nuclei with distinct nucleoli. They had compact granular cytoplasm containing few electron dense granules (approximately like to those of $\alpha$-cells) situated at one cell pole (Figure 17).

Both $\alpha$ - and $\delta$-cells were diffused singly throughout the pancreatic islet in between the numerous $\beta$-cells. Although, a-cells could be seen adjacent or close to capillaries (Figure 15). The capillaries were fenestrated in type with narrow or wide calipers (Figure 15). All pancreatic cells approximately share same organelles that include; rER (Figure17), mitochondria and Golgi apparatus.

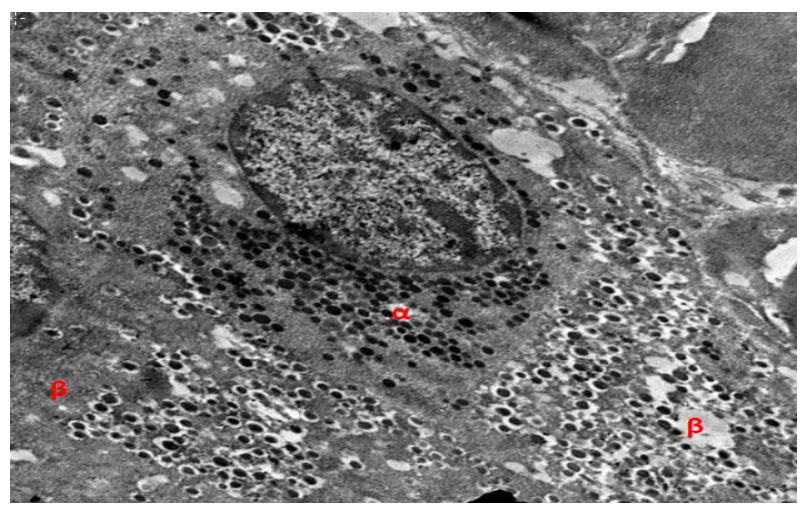

Figure 16: Transmission electron micrograph of rabbit pancreas (pancreatic islet) showing: $\beta$-cells have electron dense cores with clear halo zones and $\alpha$-cell has electron dense granules. $12000 \mathrm{X}$.

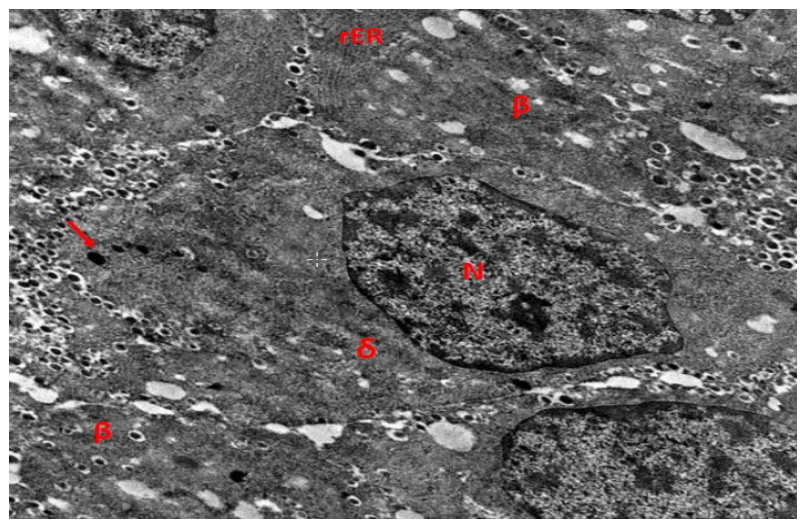

Figure 17: Transmission electron micrograph of rabbit pancreas (pancreatic islet) showing: $\delta$-cell and its nucleus $(\mathrm{N})$, electron dense granules at one pole of $\delta$ cell (arrow) and $\beta$-cell and its rER. $12000 \mathrm{X}$. 


\section{Discussion}

The present study had discussed the normal morphological structure of rabbit pancreas with focusing on its endocrine part, because its functional significance and any disturbance to this function might cause sickness of diabetes. Recently, diabetes had become widespread disease encountered in both farm and wild animals which they were affected with this illness naturally and experimentally $(9,10)$.

In native rabbit, few pancreatic acini appeared as typical units consisting of central lumen, surrounded by acinar cells, while plurality of acini did not have this classical form. Bockman (11) in human pancreas interpreted this description, where he mentioned that several acini might be created on the sides of a duct as it courses through a lobule, so acinus might be the terminal structure a duct, or might be formed en passage. An acinus might be interpolated between ducts.

Our results revealed that the apical lateral cell membranes of both acinar and ductal cells were adhering by zonulae occludens and zonulae adherens. The zonulae occludens (tight junction) form a seal between adjacent cells due to interactions between the transmembrane proteins of each cell (12). Kern (13) sated that intercellular tight junctions between ductal cells and between acinar cells played a major role in preventing entry of the duct system. Furthermore, the last researcher pointed out that the safety of the duct system was needful to prevent leakage exocrine enzymes into the interstitium where they caused tissue harm and this was might be led to pancreatitis.

In the present study, the lateral cell membranes of adjacent ductal cells showed numerous notable interdigitating by using TEM. This was interpretation why the lateral cell boundaries were not identified when using LM.

One of the most unfamiliar things about my research was the presence of the $\alpha$ - and $\beta$-cells within the duct system (mainly in the interlobular and the accessory pancreatic ducts). These cells exist as a single cell and in partial manner between the ductal cells, but never reach to lumen. Several investigators had confirmed the occurrence of these cells in the duct system of adult humans and mammals (14-16). Fujita et al. (16) showed apparent two kinds of endocrine cells; the first cell type inserted within the ductal cell and never reach to luminal surface, so was termed closed type. Unlike to this, the other cell type was known as open type that reached to the surface of epithelium.

According to the description of Fujita et al. (16), the endocrine cells in the present work were regarded as "closed" type. On the other hand, Blaine et al. (14) discovered that $\beta$-cells near to acinar-derived ductal cells arose from $\beta$-cells that were exist previously, suggesting that islet endocrine cells could intercalate into hyperplastic ducts as they developed. Therefore, both hyperplastic ductal cells and their associated $\beta$-cells arose from the same cell of origin.

At the ultrastructure level, endocrine pancreatic cells; $\beta$, $\alpha$ and $\delta$ in native rabbit could be identified by the differences in their granules. The granules of $\beta$-cells were exemplary prominent which composed of electron dense cores with clear halo zones. This information was agreement with finding of (17) in rabbit and opossum as well as of (18) in mouse and human. In native rabbit and in consistence with other researches $(18,19)$ who found that $\alpha$-cell possessed very electron dense granules.

The granules of $\delta$-cells of native rabbit were electron dense granules located at one cell pole, while the same granules had electron lucent profile in opossum (17). Moreover, the latter author recorded that the cytoplasm of $\delta$-cells was compact and granular like our results. The for mentioned data revealed that the granules of the pancreatic endocrine cells had a specific appearance for different species.

Based on the histological and ultrastructural observations of present report, pancreatic islets of native rabbits were considered as multicellular islets consisting of $\beta$-, $\alpha$ - and $\delta$-cells. The installation of pancreatic islets might differ both among different species and also within the same species $(20,21)$. In the native rabbit, $\beta$-cells were placed in the center of pancreatic islets, while the $\alpha$-cells towards periphery or vice versa. Ahmed (22) in albino rat, Balasundaram (23) in goat, Ladukar and Pandit (24) in buffalo, Mahesh et. al. (25) in sheep and goat, Meshram et al. (26) in caprine, Jagapath et al. (27) in cat recorded that $\beta$-cells occupied the center of the islet whereas $\alpha$-cells were located at periphery. Differently, other investigators like Dhoolappa (28) in Indian donkey and Karaca et al. (29) in Van cat documented that $\alpha$-cells were tend to occur in the center of the islet and $\beta$-cells towards the periphery. Tsuchitani et al. (30) in minipig mentioned that both $\alpha$ - and $\beta$-cells were present in all parts of the islet, intermingling with each other. Kim et al. (31) and Steiner et al. (32) had explain that the variability of pancreatic endocrine cells distribution in different species might be due to habits of feeding, physiological functions and pathological conditions like diabetes and obesity rather than the difference in species.

The present work recorded that the pancreatic islets were furnished by numerous capillaries which they were situated either in the center of islets or they located at their periphery. Ultrastructurally, these capillaries were fenestrated in type with narrow or wide calipers. According to the size of pancreatic islets and location of capillaries in association with the islets, there were two systems of blood supply. In the small islet, the capillaries had peripheral position and $\beta$-cells were centrally located surrounding by 
non- $\beta$-cells. In the large islets, the capillaries were centrally located and associating with non- $\beta$-cells (33). This variance in blood supply was not casual but divided the central $\beta$ cells into units, which had ready arrival to capillaries (18). Moreover, Pfeifer et al. (34) suggested that several $\beta$-cells in rodent islets were situated at distance from capillaries; in this case, the cells liberated content of their granules into extracellular spaces and thus insulin diffuses to the capillaries.

\section{Conclusion}

In native rabbit pancreas, the used of TEM revealed accurate details that could not easily be differentiated with classical staining methods; cytological features of acinar, ductal and endocrine cells as well as presence of $\alpha$ - or $\beta$ cells within the duct system were examples for this.

\section{References}

1. Aughey E, Frye FL. Comparative veterinary histology with clinical correlates. London: Manson Publishing Ltd; 2001. 327-328 p.

2. Bacha WJ, Bacha LM. Color atlas of veterinary histology. $2^{\text {nd }}$ ed. Maryland: Lippincott Williams \& Wilkins Baltimore; 2000. 121 p.

3. Pandol SJ. Normal pancreatic function. Pancreapedia: Exocrine pancreas knowledge base. DOI: 10.3998/panc.2015.17.

4. Seymour PA, Bennett WR, Slack JMW. Fission of pancreatic islets during postnatal growth of the mouse. J Anat. 2004;204:103-116. doi: 10.1111/j.1469-7580.2004.00265.x

5. Hristov H, Kostov D, Vladova D. Topographical anatomy of some abdominal organs in rabbits. Trakia J Sci. 2006;4(3):7-10.

6. Bancroft JD, Gamble M. Theory and practice of histological techniques. $6^{\text {th }}$ ed. New York: Churchill Livingstone; 2008. 87- 88, $177,203,225 \mathrm{p}$.

7. Culling CFA, Alison RT, Barr WT. Cellular pathology technique. $4^{\text {th }}$ ed. London: Butterworth Co Ltd; 1985. 478- 479 p.

8. Al-Saffar FJ, Al-Hasnawy AHA. Histomorphological developmental study of advanced postnatal of the pancreas of local rabbit. J Biol Sci. 2014;14(6):387-402. doi=10.3923/jbs.2014.387.402

9. Behrend E, Holford A, Lathan P, Rucinsky R, Schulman R. Diabetes management guidelines for dogs and cats. J Am Anim Hosp Assoc. 2018;54:1-21. DOI 10.5326/JAAHA-MS-6822

10. Niaz K, Maqbool F, Khan F, Hassan FI, Momtaz S, Abdollahi M. Comparative occurrence of diabetes in canine, feline, and few wild animals and their association with pancreatic diseases and ketoacidosis with therapeutic approach. Vet World. 2018;11(4):410422. doi: 10.14202/vetworld.2018.410-422

11. Bockman DE. Anatomy of the pancreas. $2^{\text {nd }}$ ed. New York: Raven Press; $1993.7 \mathrm{p}$.

12. Mescher AL. Junqueira's basic histology text and atlas. $13^{\text {th }}$ ed. USA: McGraw-Hill Education; 2013. 327-328 p.

13. Kern HF. Fine structure of the human exocrine pancreas. In: Van L, Go W, editors. The pancreas: Biology, pathobiology, and disease, $2^{\text {nd }}$ ed, New York: Raven Press; 1993. 9-19 p.

14. Blaine SA, Ray KC, Anunobi R, Gannon MA, Mary K, Washington MK, Means AL. Adult pancreatic acinar cells give rise to ducts but not endocrine cells in response to growth factor signaling. Dev. 2010;137(14):2289-2296. doi: 10.1242/dev.048421

15. Egerbacher M, Böck P. Morphology of the pancreatic duct system in mammals. Micro Res Tech. 1997;37:407-417. DOI: 10.1002/ (SICI)1097-0029(19970601)37:5/6<407::AID-JEMT5>3.0.CO;2-A
16. Fujita T, Kanno T, Kobayashi S. The Paraneuron. Tokyo Dis. 1998;8:167-172.

17. Munger BL, Caramia F, Lacy PE. The ultrastructural basis for the identification of cell types in the pancreatic islets. II. Rabbit, dog and opossum. Zeitschrift für Zellforschung. 1965;67:776-798. DOI:10.1007/BF00339301

18. Brereton MF, Vergari E, Zhang Q, Clark A. Alpha-, Delta- and PPcells. Are they the architectural cornerstones of islet structure and coordination? J Histochem Cytochem. 2015:63(8):575-591. doi: $10.1369 / 0022155415583535$.

19. Deconinck JF, Potvliege PR, Gepts W. The ultrastructure of the human pancreatic islets. I. The islets of adults. Diabetologia. 1971;7:266-282. doi: 10.1007/BF01211879

20. Reddy S, Bibby NJ, Elliott RB. Cellular distribution of insulin, glucagon, pancreatic polypeptide hormone and somatostatin in the fetal and adult pancreas of the guinea pig: a comparative immunohistochemical study. Eur J Cell Biol. 1985;8:301-305.

21. Wieczorek G, Pospischil A, Perentes E. A comparative immunohistochemical study of pancreatic islets in laboratory animals (rats, dogs, minipigs, nonhuman primates). Exp Toxicol Pathol. 1998;50:151-172. DOI: 10.1016/S0940-2993(98)80078-X

22. Ahmed R. Gross, histological and histochemical studies on the pancreas of albino (Rattus norvegicus) [MVSc thesis]. Tirupati: University of Sri Venkateswara Veterinary; 2013.

23. Balasundaram K. Histomorphology of Pancreas in Goats. J Pharm Phytochem. 2018;1:1711-1713. DOI: JPP 2018; SP1: 1711-1713

24. Ladukar ON, Pandit RV. Nerve supply to buffalo pancreas, periinsular plexus. Indian Vet J. 1995;72(10):1061-1064. https://eurekamag.com/research/009/082/009082325.php

25. Mahesh GKM, Ashok P, Girish HM, Awati A. Comparative histomorphology of endocrine pancreas in Deccani sheep and Bidri goat. MOJ Anat Physiol. 2017;3(1):1-3. DOI: 10.15406/mojap.2017.03.00079

26. Meshram BN, Dalvi RS, Bhamburkar VR, Banubakode SB, Nandeshwar NG. Histomorphological studies on caprine pancreas with reference to ageing. Indian J Vet Anatomy. 2001;13(2):130-133.

27. Jagapath RP, Prasanth BA, Patki HS, Chandersekhara RTS. Anatomy of the pancreas of domestic cat. Indian Vet J. 2012;89(10):72-74.

28. Dhoolappa M. Macro and micro anatomy of liver and pancreas in Indian donkey [MVSc thesis]. Dharwad: University of Agricultural Sciences; 2002.

29. Karaca T, Kara A, Şimsek N, Uslu S, Tekiner D, Yörük M. Immunohistochemical distribution of glucagon, insulin, somatostatin, gastrin and serotonin-containing cells in the pancreas of the Van cat. Turk J Vet Anim Sci. 2014;38:304-311. DOI: 10.3906/vet-1309-72

30. Tsuchitani M, Sato J, Kokoshima H. A comparison of the anatomical structure of the pancreas in experimental animals. J Toxicol Pathol. 2016;29:147-154. doi: 10.1293/tox.2016-0016

31. Kim A, Miller K, Jo J, Kilimnik G, Wojcik P, Hara M. Islet architecture: a comparative study. Islets. 2009;1:129-136. doi: 10.4161/isl.1.2.9480.

32. Steiner DJ, Kim A, Miller K, Hara M. Pancreatic islet plasticity: interspecies comparison of islet architecture and composition. Islets. 2010;2:135-145. DOI: $10.4161 /$ isl.2.3.11815

33. Cabrera O, Berman DM, Kenyon NS, Ricordi C, Berggren PO, Caicedo A. The unique cytoarchitecture of human pancreatic islets has implications for islet cell function. Proc Natl Acad Sci. 2006;103:2334-2339. DOI: 10.1073/pnas.0510790103

34. Pfeifer CR, Shomorony A, Aronova MA, Zhang G, Cai T, Xu H, Notkins AL, Leapman RD. Quantitative analysis of mouse pancreatic islet architecture by serial block-face SEM. J Struct Biol. 2015;189(1):44-52. DOI: 10.1016/j.jsb.2014.10.013

35. Jörns A, Barklage E, Grube D. Heterogeneities of the islets in the rabbit pancreas and the problem of "paracrine" regulation of islet cells. Anat Embryol. 1988;178:297-307. DOI: 10.1007/bf00698661 